\title{
Tinjauan Keamanan Lereng Di Desa Tomberabu 1 Kecamatan Ende Kabupaten Ende
}

\author{
*Veronika Miana Radja ${ }^{1}$, Ireneus Kota Dua ${ }^{2}$ \\ ${ }^{1,2,3}$ Program Studi Teknik Sipil, Fakultas Teknik, Univesitas Flores, Ende NTT \\ *) Correspondence e-mail: veronika_mira@yahoo.com
}

\begin{abstract}
ABSTRAK
Secara geografis, Desa Tomberabu 1 berjarak kurang lebih $15 \mathrm{~km}$ dari Kota Ende dengan ketinggian wilayah ratarata 780 meter dari permukaan laut dan keadaan topografi terdiri dari bukit dengan kemiringan berkisar $30^{\circ}-60^{\circ}$. Mayoritas masyarakat Desa Tomberabu 1 berprofesi sebagai petani dan bermukim di sepanjang lereng yang juga merupakan lahan perkebunanan dan ladang penduduk. Sehngga perlu dipertimbangkan keamanannya dari bahaya longsor, mengingat daerah ini merupakan wilayah dengan intensitas curah hujan cukup tinggi.Analisis ini dilakukan untuk memperoleh deskripsi sampel tanah dan data berupa angka yang akan digunakan untuk mencari nilai faktor keamanan lereng dengan kemiringan mendekati $90^{\circ}$ setinggi $10 \mathrm{~m}$. Nilai yang diperoleh adalah $\mathrm{SF}=$ 1,003 < 1,2, nilai ini menyatakan bahwa lereng tersebut dalam kondisi tidak aman. Sehingga perlu dilakukan penanggulangan kelongsoran antara lain dengan mengubah tinggi lereng dengan membuat teras pada ketiggian 5 $m$, dan diperoleh angka keamanannya $S F=1,318$. Walaupun demikian masih perlu juga untuk melakukan perencanaan saluran yang baik serta pembuatan dinding penahan yang sesuai dengan kondisi tanahnya
\end{abstract}

Kata kunci ; lereng kritis, faktor keamanan, longsor

\section{PENDAHULUAN}

Kecamatan Ende merupakan salah satu wilayah kecamatan yang terletak di bagian utara ibukota Kabupaten Ende dengan luas $16,06 \mathrm{~km}^{2}$. Salah satu desa yang berada dalam wilayah administrasi Kecamatan Ende adalah Desa Tomberabu 1. Secara geografis, Desa Tomberabu 1 berjarak kurang lebih $15 \mathrm{~km}$ dari Kota Ende, terdiri dari beberapa dusun atau kampung seperti: Nuareko, Tiwurande, Rombonata, Bangupau, Rateseto, Anabha, Pu'umbindi, dan Mbegho. Berdasarkan data dari Badan Pusat Statistik Kabupaten Ende, jumlah penduduk Desa Tomberabu 1 pada tahun 2013 sebesar 1.162 jiwa. Ketinggian wilayah Desa Tomberabu 1 rata-rata 780 meter dari permukaan laut dan keadaan topografi sebagian besar daerah ini terdiri dari bukit dengan kemiringan berkisar $30^{\circ}-60^{\circ}$. Mayoritas masyarakat Desa Tomberabu 1 berprofesi sebagai petani dan bermukim di sepanjang lereng yang juga merupakan lahan perkebunanan dan ladang penduduk. Keberadaan pemukiman penduduk pada bagian lereng perbukitan tidak jauh dari lahan perkebunan perlu dipertimbangkan keamanannya dari bahaya longsor, mengingat daerah ini merupakan wilayah dengan intensitas curah hujan cukup tinggi.

Menurut data hasil survei kerjasama Teknis Indonesia - Jerman Bidang Mitigasi Bencana Geologi, wilayah Desa Tomberabu 1 termasuk daerah dengan intensitas curah hujan tinggi yang dapat mengakibatkan erosi dan tanah longsor. Selain itu, kerentanan gerakan tanah dan potensi bahaya seismotektonik juga tergolong tinggi.

Oleh karena itu perlu untuk melakukan kajian mengenai keamanan lereng dalam hubungannya dengan keamanan pemukiman dan rumah penduduk serta alternatif pencegahan bahaya keruntuhan di Desa Tomberabu 1 Kecamatan Ende Kabupaten Ende. 


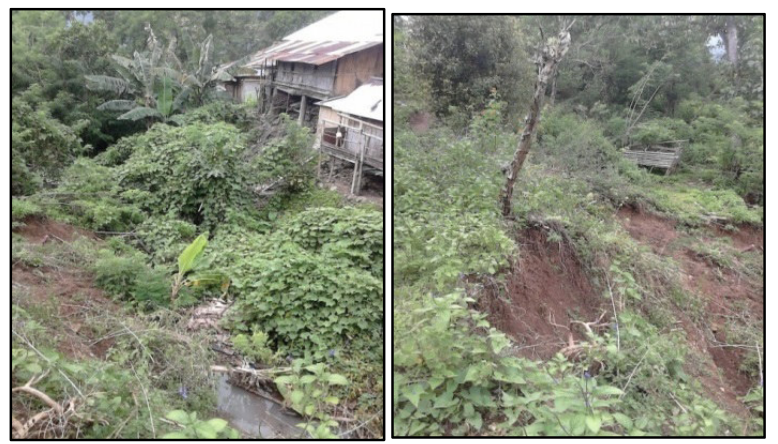

Gambar 1. Lokasi Lereng di Desa Tomberabu 1 Sumber : Dokumentasi Pribadi

\section{Kekuatan Gesser Tanah}

Keaktifan lereng adalah proses perpindahan masa tanah atau batuan dimana:

$$
\begin{array}{ll}
\tau=c & +\sigma \tan \emptyset \\
c & =\text { Kohesi tanah yang sebenarnya } \\
\varnothing & =\text { Sudut geser tanah } \\
\sigma & =\text { Tegangan normal yang bekerja. }
\end{array}
$$

Kekuatan geser tanah yang berada dalam kondisi jenuh diperlukan suatu pengertian mengenai peranan dari tekanan air pori.

$$
\sigma^{\prime}=\sigma-u
$$

Maka kekuatan geser efektif;

Dimana:

$$
\tau f=c^{\prime}+\sigma^{\prime} \tan \emptyset
$$

$$
\begin{array}{ll}
\tau_{\mathrm{f}} & =\text { Kuat geser efektif } \\
\mathrm{c} & =\text { Kohesi (pengaruh tarikan antar partikel). } \\
\sigma & =\text { Tegangan normal pada bidang yang ditinjau. } \\
\varnothing & =\text { Sudut geser dalam. }
\end{array}
$$

Analisis stabilitas didasarkan pada konsep umum keseimbangan batas (General Limit Equilibrium), untuk menghitung faktor keamanan (SF) yang melawan gaya runtuh pada stabilitas lereng tersebut.

$$
S F=\frac{S_{f}}{S_{d}}
$$

Dengan :

$\mathrm{SF} \quad=$ Angka kematian terhadap kekuatan tanah

$\mathrm{S}_{\mathrm{f}} \quad=$ kekuatan geser rata-rata dari tanah $\left(\mathrm{kN} / \mathrm{m}^{2}\right)$

$\mathrm{S}_{\mathrm{d}} \quad=$ Tegangan geser rata-rata yang bekerja sepanjang bidang $\quad$ longsor $\mathrm{kN} / \mathrm{m}^{2}$ )

Momen penahan yang ada sebesar:

$$
M_{\text {penahan }}=r\left(c^{\prime} b+W t \cos \alpha \tan \phi^{\prime}\right)
$$

Komponen tangensial Wt, bekerja sebagai penyebab Iongsoran yang menimbulkan momen penyebab sebesar:

$$
M_{\text {penyebab }}=(W t \sin \alpha) * r
$$

Faktor keamanan dari lereng menjadi:

$$
F K=\frac{\Sigma\left(c^{`} b+W t \cos \alpha \tan \phi^{\prime}\right)}{\Sigma W t \sin \alpha}
$$


Jika lereng terendam air atau jika muka air tanah di atas kaki lereng, maka tekanan air pori akan bekerja pada dasar elemen yang ada di bawah air tersebut. Dalam hal ini tahanan geser harus diperhitungkan yang efektif sedangkan gaya penyebabnya tetap diperhitungkan secara total, sehingga rumus menjadi:

$$
F K=\frac{\Sigma\left[\left(c^{\prime} b+(W t \cos \alpha-u b) \tan \phi^{\prime}\right)\right]}{\Sigma W t \sin \alpha}
$$

\section{METODE}

Penelitian ini merupakan rangkaian proses yang saling berkaitan satu sama lain, dimana hasil dari proses sebelumnya merupakan masukan bagi proses berikutnya. Pengujian laboratorium dilakukan untuk mengetahui karakteristik fisik dan karakteristik mekanis tanah sebagai proses awal, sebelum dilakukannya analisis stabilitas lereng untuk memperoleh angka keamanan (safety factor) lereng.

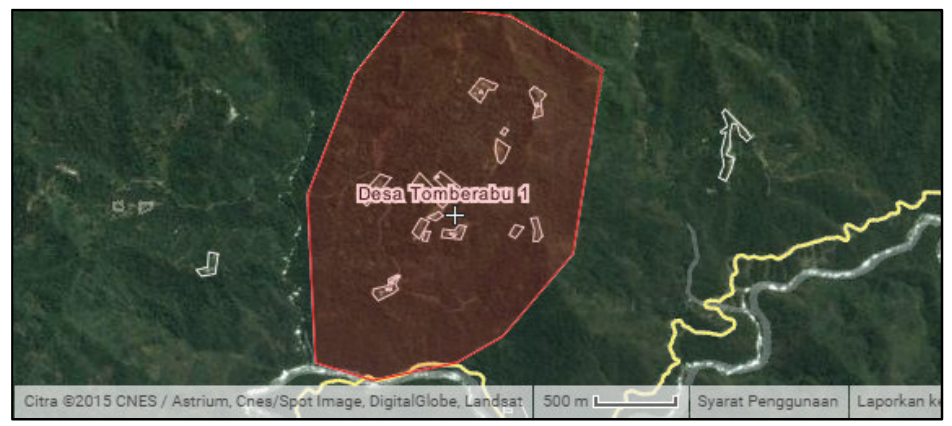

\section{Gambar 2. Lokasi Pengambilan Sampel di Desa Tomberabu 1 Sumber: http://www.google.com/maps/}

Analisis ini dilakukan untuk memperoleh deskripsi sampel tanah dan data berupa angka yang akan digunakan untuk mencari nilai faktor kemanan lereng untuk tebing setinggi $10 \mathrm{~m}$ dan $5 \mathrm{~m}$. Nilai ketinggian tersebut berdasarkan anggapan dimana lereng pada kondisi awal setinggi $10 \mathrm{~m}$, lalu dilakukan pemotongan bagian atasnya sehingga membentuk susunan lereng dengan ketinggian masing-masing $5 \mathrm{~m}$.

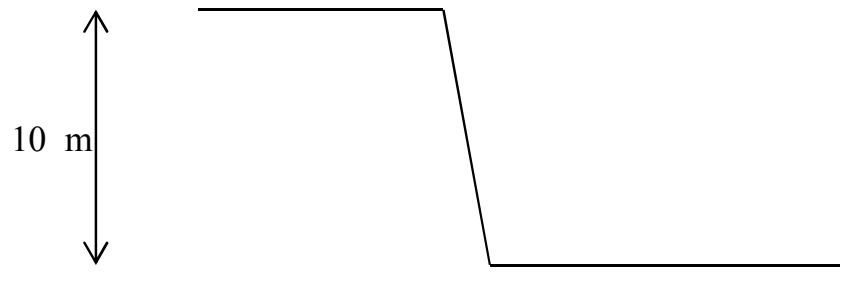

Gambar 3. Tinggi lereng kondisi awal

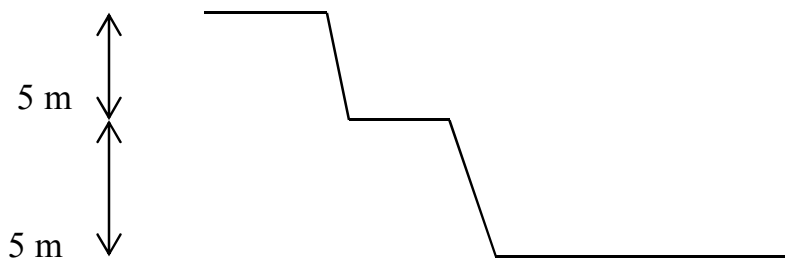

Gambar 4. Kondisi lereng setelah dipotong 


\section{HASIL DAN PEMBAHASAN}

Hasil pengujian sifat fisik sampel tanah dari keempat wilayah Desa Tomberabu selengkapnya dapat diuraikan sebagai berikut:

Tabel 1. Sifat Fisik Tanah di Lokasi Dusun Nuareko

\begin{tabular}{llllll}
\hline No & Jenis Pengujian & Satuan & Titik 1 & Titik 2 & Rata-rata \\
\hline 1 & Kadar Air & $\%$ & 22,19 & 21,70 & 21,95 \\
2 & Berat Volume Basah & $\mathrm{gr} / \mathrm{cm}^{3}$ & 2,65 & 1,84 & 2,24 \\
3 & Berat Volume Kering & $\mathrm{gr} / \mathrm{cm}^{3}$ & 1,17 & 1,39 & 1,28 \\
4 & Angka Pori & & 0,24 & 0,81 & 0,52 \\
5 & Porositas & $\%$ & 18,76 & 44,74 & 31,75 \\
6 & Derajat Kejenuhan & $\%$ & 2,96 & 0,76 & 1,86 \\
7 & Berat Jenis & $\mathrm{gr} / \mathrm{cm}^{3}$ & 2,66 & 2,68 & 2,67 \\
8 & Batas cair & $\%$ & 55,27 & 45,89 & 50,58 \\
9 & Batas Plastis & $\%$ & 45,30 & 37,50 & 41,40 \\
10 & Indeks Plastisitas & & 9,96 & 8,39 & 9,18 \\
11 & Kerikil & $\%$ & 3,97 & 4,24 & 4,11 \\
12 & Pasir & $\%$ & 25,06 & 23,04 & 24,05 \\
13 & Lanau & $\%$ & 39,75 & 39,41 & 39,58 \\
14 & Lempung & $\%$ & 31,21 & 33,32 & 32,26 \\
15 & USCS & $\mathrm{CL}$ & Lempung dengan plastisitas rendah \\
16 & AASHTO & A-5 & Tanah berlanau & \\
\hline
\end{tabular}

Sumber : Hasil Analisis Data

Dari table 1. Menunjukkan bahwa jenis tanah menurut USCS masuk kategori CL (Lempung dengan plastisitas rendah). Sedangkan enurut AASTHO kategori A-5 (Tanah berlanau).

Tabel 2. Sifat Fisik Tanah di Lokasi Dusun Tiwurande

\begin{tabular}{llllll}
\hline No & Jenis Pengujian & Satuan & Titik 1 & Titik 2 & Rata-rata \\
\hline 1 & Kadar Air & $\%$ & 21,81 & 21,59 & 21,70 \\
2 & Berat Volume Basah & $\mathrm{gr} / \mathrm{cm}^{3}$ & 1,62 & 1,61 & 1,61 \\
3 & Berat Volume Kering & $\mathrm{gr} / \mathrm{cm}^{3}$ & 1,14 & 1,13 & 1,14 \\
4 & Angka Pori & & 1,01 & 1,07 & 1,04 \\
5 & Porositas & $\%$ & 50,28 & 51,63 & 50,95 \\
6 & Derajat Kejenuhan & $\%$ & 0,58 & 0,57 & 0,58 \\
7 & Berat Jenis & $\mathrm{gr} / \mathrm{cm}^{3}$ & 2,67 & 2,68 & 2,67 \\
8 & Batas cair & $\%$ & 47,54 & 48,26 & 47,90 \\
9 & Batas Plastis & $\%$ & 36,80 & 37,36 & 37,08 \\
10 & Indeks Plastisitas & & 10,74 & 10,89 & 10,82 \\
11 & Kerikil & $\%$ & 5,06 & 4,11 & 4,58 \\
12 & Pasir & $\%$ & 29,54 & 24,05 & 26,80 \\
13 & Lanau & $\%$ & 35,82 & 39,58 & 37,70 \\
14 & Lempung & $\%$ & 29,57 & 32,26 & 30,92 \\
15 & USCS & $\mathrm{CL}$ & Lempung dengan plastisitas rendah \\
16 & AASHTO & $\mathrm{A}-5$ & \multicolumn{3}{c}{ Tanah berlanau } \\
\hline
\end{tabular}

Sumber : Hasil Analisis Data 
Dari table 2. Menunjukkan bahwa jenis tanah menurut USCS masuk kategori CL (Lempung dengan plastisitas rendah). Sedangkan enurut AASTHO kategori A-5 (Tanah berlanau).

Tabel 3. Sifat Fisik Tanah di Lokasi Dusun Bangupau

\begin{tabular}{clllll}
\hline No & Jenis Pengujian & Satuan & Titik 1 & Titik 2 & Rata-rata \\
\hline 1 & Kadar Air & $\%$ & 21,29 & 21,36 & 21,33 \\
2 & Berat Volume Basah & ${\mathrm{gr} / \mathrm{cm}^{3}}^{3}$ & 1,96 & 1,98 & 1,97 \\
3 & Berat Volume Kering & $\mathrm{gr} / \mathrm{cm}^{3}$ & 1,43 & 1,35 & 1,39 \\
4 & Angka Pori & & 0,66 & 0,68 & 0,67 \\
5 & Porositas & $\%$ & 39,79 & 40,46 & 40,13 \\
6 & Derajat Kejenuhan & $\%$ & 0,90 & 0,90 & 0,90 \\
7 & Berat Jenis & $\mathrm{gr} / \mathrm{cm}^{3}$ & 2,67 & 2,66 & 2,67 \\
8 & Batas cair & $\%$ & 45,81 & 45,49 & 45,65 \\
9 & Batas Plastis & $\%$ & 35,33 & 35,22 & 35,28 \\
10 & Indeks Plastisitas & & 10,48 & 10,27 & 10,37 \\
11 & Kerikil & $\%$ & 4,52 & 4,65 & 4,58 \\
12 & Pasir & $\%$ & 27,30 & 26,29 & 26,80 \\
13 & Lanau & $\%$ & 37,79 & 37,62 & 37,70 \\
14 & Lempung & $\%$ & 30,39 & 31,44 & 30,92 \\
15 & USCS & $\mathrm{CL}$ & Lempung dengan plastisitas rendah \\
16 & AASHTO & $\mathrm{A}-5$ & Tanah berlanau \\
\hline Sumber : Hasil Analisis Data & \multicolumn{4}{l}{} \\
\hline
\end{tabular}

Dari table 3. Menunjukkan bahwa jenis tanah menurut USCS masuk kategori CL (Lempung dengan plastisitas rendah). Sedangkan enurut AASTHO kategori A-5 (Tanah berlanau).

Tabel 4. Sifat Fisik Tanah di Lokasi Dusun Anabha

\begin{tabular}{|c|c|c|c|c|c|}
\hline No & Jenis Pengujian & Satuan & Titik 1 & Titik 2 & Rata-rata \\
\hline 1 & Kadar Air & $\%$ & 22,51 & 22,31 & 22,41 \\
\hline 2 & Berat Volume Basah & $\mathrm{gr} / \mathrm{cm}^{3}$ & 1,98 & 2,02 & 2,00 \\
\hline 3 & Berat Volume Kering & $\mathrm{gr} / \mathrm{cm}^{3}$ & 1,16 & 1,59 & 1,38 \\
\hline 4 & Angka Pori & & 0,64 & 0,65 & 0,64 \\
\hline 5 & Porositas & $\%$ & 39,02 & 39,31 & 39,17 \\
\hline 6 & Derajat Kejenuhan & $\%$ & 0,92 & 0,95 & 0,93 \\
\hline 7 & Berat Jenis & $\mathrm{gr} / \mathrm{cm}^{3}$ & 2,62 & 2,65 & 2,63 \\
\hline 8 & Batas cair & $\%$ & 44,78 & 43,27 & 44,02 \\
\hline 9 & Batas Plastis & $\%$ & 33,65 & 33,90 & 33,78 \\
\hline 10 & Indeks Plastisitas & & 11,12 & 9,37 & 10,25 \\
\hline 11 & Kerikil & $\%$ & 4,60 & 4,42 & 4,51 \\
\hline 12 & Pasir & $\%$ & 23,55 & 25,88 & 24,71 \\
\hline 13 & Lanau & $\%$ & 39,09 & 38,33 & 38,71 \\
\hline 14 & Lempung & $\%$ & 32,76 & 31,37 & 32,07 \\
\hline 15 & USCS & $\mathrm{CL}$ & \multicolumn{3}{|c|}{ Lempung dengan plastisitas rendah } \\
\hline 16 & AASHTO & A-5 & \multicolumn{3}{|c|}{ Tanah berlanau } \\
\hline
\end{tabular}

Sumber : Hasil Analisis Data 
Dari table 1. Menunjukkan bahwa jenis tanah menurut USCS masuk kategori CL (Lempung dengan plastisitas rendah). Sedangkan enurut AASTHO kategori A-5 (Tanah berlanau).

Tabel 5. Rekapitulasi Hasil Pengujian Kuat Geser Langsung

\begin{tabular}{lcccc}
\hline Lokasi & Titik & \multicolumn{1}{c}{ Slope } & Kohesi ( C ) & Sudut Geser ( Ø ) \\
\hline \multirow{2}{*}{ Nuareko } & 1 & 0,482 & $\mathbf{0 , 2 9 5}$ & 25,730 \\
& 2 & 0,446 & 0,345 & 24,048 \\
Tiwurande & 1 & 0,446 & 0,345 & 24,048 \\
& 2 & 0,518 & 0,328 & 27,367 \\
Bangupau & 1 & 0,536 & 0,320 & 28,167 \\
& 2 & 0,518 & 0,328 & 27,367 \\
Anabha & 1 & 0,429 & 0,337 & $\mathbf{2 3 , 1 8 9}$ \\
& 2 & 0,625 & 0,312 & 31,993 \\
\hline
\end{tabular}

Sumber : Hasil Analisis Data

Nilai yang diambil untuk analisis stabilitas lereng adalah pada kondisi tanah terlemah (nilai sudut gesernya terkecil) yaitu pada desa Anabha titik 1 dengan nilai .sudut geser $=23,189^{\circ}$. Dengan menggunakan program geo-Studio, diperoleh nilai faktor keamanan lereng terkritis untuk tebing dengan ketinggian $10 \mathrm{~m}$ adalah $=1,003$ dengan kondisi bidang longsor seperti pada Gambar 5 .

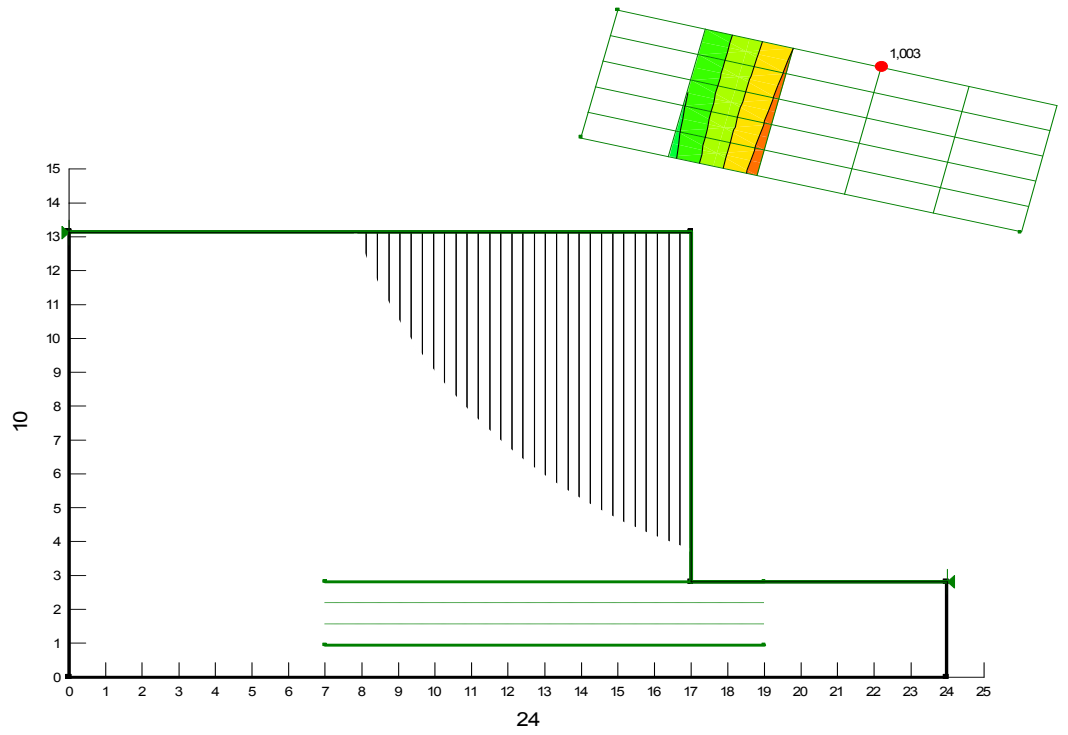

Gambar 5. Lereng dengan ketinggian $10 \mathrm{~m}$

Nilai ini menyatakan bahwa lereng tersebut dalam kondisi tidak aman, karena nlai $\mathrm{SF}=1,003<$ 1,2. Oleh karena itu perlu dilakukan penanggulangan longsor antara lain dengan cara:

1. Mengubah geometri lereng

2. Mengendalikan air permukaan

3. Mengendalikan air rembesan

4. Penambatan

Hasil analisa setelah mengubah geometri lereng yakni dengan membuat teras pada ketinggian $5 \mathrm{~m}$, maka nilai keamanan yang diperoleh adalah $=1,318$ dengan bidang longsor seperti pada Gambar 6 . 


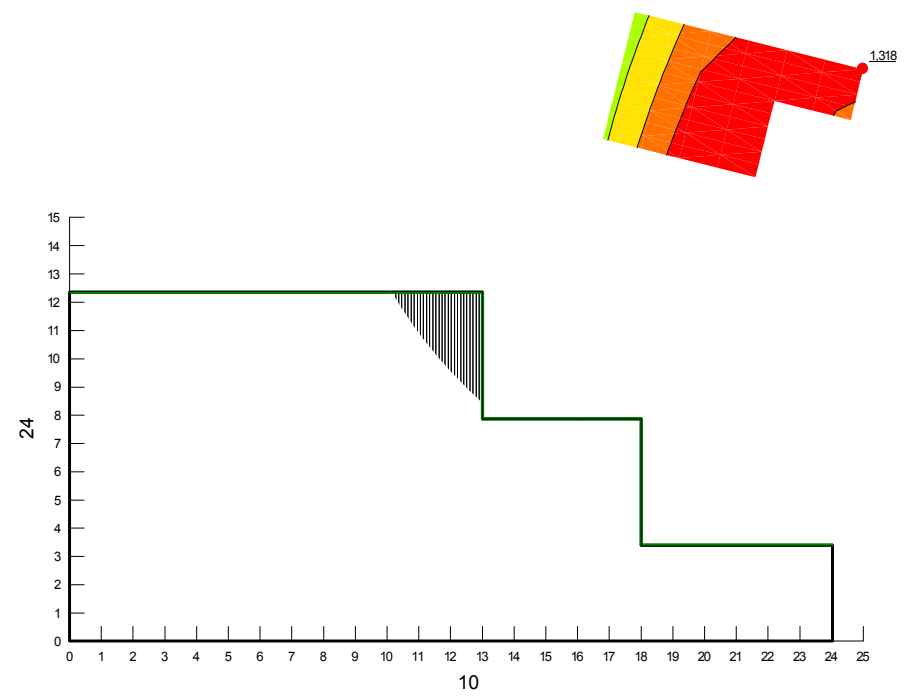

Gambar 6. Lereng dengan ketinggian bersusun masing-masing $5 \mathrm{~m}$

Selanjutnya perlu melakukan perencanan saluran yang baik dan dinding penahan yang sesuai dengan kondisi tanah tersebut.

\section{KESIMPULAN}

Berdasarkan hasil analisis keamanan lereng menggunakan program GeoStudio 2007, maka penulis dapat menyimpulkan bahwa kondisi lereng di Desa Tomberabu sudah sangat kritis karena nilai SF $=1,003<$ 1,2. Oleh karena itu perlu dilakukan pembuatan teras pada ketinggian $5 \mathrm{~m}$ dengan $\mathrm{SF}=1,318$ serta perencanaan saluran serta dinding penahan yang baik.

\section{DAFTAR PUSTAKA}

Browles. (1986). Mekanika Tanah (Sifat-Sifat Fisik dan Geoteknis Tanah). Edisi Kedua. Erlangga: Jakarta

Das, B.M. (1988). Mekanika Tanah (Prinsip-Prinsip Rekayasa Geoteknis). Penerbit Erlangga: Jakarta

Departemen Energi dan Sumber Daya Mineral Badan Geologi. Analisis Bahaya Geologi dan Risiko Kabupaten Ende, Nusa Tenggara Timur. Bandung

Departemen Pekerjaan Umum. (2004). Rekayasa Penanganan Keruntuhan Lereng Pada Tanah Residual dan Batuan. Jakarta

Departemen Pekerjaan Umum. Buku Petunjuk Teknis Perencanaan dan Penanganan Longsoran. Direktorat Jenderal Bina Marga Jakarta

Goro, G.L. (2007). Studi Analisis Stabilitas Lereng Pada Timbunan Dengan Metode Elemen Hingga. Jurnal Wahana Teknik Vol. 12 No. 1 Edisi April 2007

Hardiyatmo, C.H. (1992). Mekanika Tanah 1. Penerbit PT Gramedia Pustaka Utama: Jakarta (2010). Mekanika Tanah 2. Edisi Kelima. Gadjah Mada University Press: Yogyakarta

Pranata, H. (2010). Analisis Dinding Penahan Tanah Dengan Perhitungan Manual dan Kontrol GayaGaya Dalam Yang Bekerja Pada Dinding Penahan Tanah Dengan Metode Sap2000 PlaneStrain. Skripsi Fakultas Teknik Universitas Negeri Yogyakarta

Ramadhani, S. (2010). Perencanaan Dinding Penahan Tipe Gravitasi Pada Lokasi Bukit BTN Teluk Palu Permai. Jurnal SMARTek, Volume 8 Nomor 1 Edisi Februari 2010.

Valefy, F. (2011). Analisa Gravity Wall dan Cantiliver Wall Ditinjau Dari Segi Ekonomis Terhadap Tinggi Yang Variatif. Tugas Akhir Departemen Teknik Sipil Fakultas Teknik Universitas Sumatera Utara Medan

Wesley, L.D. (2012). Mekanika Tanah (untuk Tanah Endapan dan Residu). Penerbit Andi: Yogyakarta 